\title{
Characterization and validation of long noncoding RNAs as new candidates in prostate cancer
}

\author{
Shengyang $\mathrm{Ge}^{1 \dagger}$, Yuanyuan $\mathrm{Mi}^{2 \dagger}$, Xiaojun Zhao ${ }^{3}$, Qingfeng Hu${ }^{1}$, Yijun Guo ${ }^{4}$, Fan Zhong ${ }^{5}$, Yang Zhang ${ }^{5}$, \\ Guowei Xia ${ }^{1^{*}}$ and Chuanyu Sun ${ }^{1 *}$ (D)
}

\begin{abstract}
Background: Long noncoding RNAs (IncRNAs) have been proved to be an important regulator in gene expression. In almost all kinds of cancers, IncRNAs participated in the process of pathogenesis, invasion, and metastasis. Meanwhile, compared with the large amounts of patients, there is rare knowledge about the role of IncRNAs in prostate cancer (PCa).
\end{abstract}

Material/Method: In this study, IncRNA expression profiles of prostate cancer were detected by Agilent microarray chip, 5 pairs of case and control specimens were involved in. Differentially expressed IncRNAs were screened out by volcano plot for constructing IncRNA-miRNA-mRNA central network. Then, the top ten up-regulated and downregulated IncRNAs were validated by qRT-PCR in another 5 tumor specimens and 7 para-cancerous/benign contrasts. Furthermore, we searched for the survival curve of the top 10 upregulated and downregulated IncRNAs.

Results: A total of 817 differentially expressed IncRNAs were filtered out by the criteria of fold change $(F C)$ and t-test $p<0.05$. Among them, 422 were upregulated, whereas 395 were downregulated in PCa tissues. Gene ontology and KEGG pathway analyses showed that many IncRNAs were implicated in carcinogenesis. Inc-MYL2-4:1 (FC $=0.00141$, $p=0.01909)$ and NR_125857 ( $F C=59.27658, p=0.00128)$ had the highest magnitude of change. The subsequent qPCR confirmed the expression of NR_125857 was in accordance with the clinical samples. High expression of PCA3, PCAT14 and AP001610.9 led to high hazard ratio while low expression of RP11-279F6.2 led to high hazard ratio.

Conclusions: Our study detected a relatively novel complicated map of IncRNAs in PCa, which may have the potential to investigate for diagnosis, treatment and follow-up in PCa. Our study revealed the expression of NR_125857 in human PCa tissues was most up-regulated. Further studies are needed to investigate to figure out the mechanisms in PCa.

Keywords: Prostate cancer, IncRNA, Microarray

\footnotetext{
*Correspondence: xiaguowei@fudan.edu.cn; zhugexianglong@163.com †'Shengyang Ge, Yuanyuan Mi and Xiaojun Zhao equally dedicated to this article

1 Department of Urology, Huashan Hospital, Fudan University, 12 Central Urumqi Rd, Shanghai 200040, P. R. China

Full list of author information is available at the end of the article
}

\begin{abstract}
Introduction
Prostate cancer $(\mathrm{PCa})$ is one of the most common malignancy in males, like in the United State, it causes estimated 191,930 cases and 33,330 deaths in 2020 [1]. PCa ranks the fifth leading cause of cancer death worldwide [2]. With the development of economy and society, China is experiencing a transition stage from a developing country into a developed country, named as "westernized
\end{abstract}

(c) The Author(s) 2020. This article is licensed under a Creative Commons Attribution 4.0 International License, which permits use, sharing, adaptation, distribution and reproduction in any medium or format, as long as you give appropriate credit to the original author(s) and the source, provide a link to the Creative Commons licence, and indicate if changes were made. The images or other third party material in this article are included in the article's Creative Commons licence, unless indicated otherwise in a credit line to the material. If material is not included in the article's Creative Commons licence and your intended use is not permitted by statutory regulation or exceeds the permitted use, you will need to obtain permission directly from the copyright holder. To view a copy of this licence, visit http://creativeco mmons.org/licenses/by/4.0/. The Creative Commons Public Domain Dedication waiver (http://creativecommons.org/publicdomain/ zero/1.0/) applies to the data made available in this article, unless otherwise stated in a credit line to the data. 
lifestyle-related cancer", so we can easily find that there is an ascendant tendency in the incidence rate of $\mathrm{PCa}$ [3]. Many conventional high-risk factors have been concerned with the period of tumorigenesis, invasion and metastasis of $\mathrm{PCa}$, including genetic, environmental and life-style factors $[4,5]$.

$\mathrm{PCa}$ is normally hormone-dependent at diagnosis indicating androgen receptor (AR) signaling is a distinctive feature in this disease [6]. The AR is a ligand-activated transcription factor typically responsive to the androgen testosterone and dihydrotestosterone [7]. Androgen deprivation therapy (ADT), urological surgery or chemical castration, is a standard treatment used in recurrent $\mathrm{PCa}$ [8]. Even though most of patients with $\mathrm{PCa}$ are treated successfully, a significant proportion of patients would develop castration-resistant prostate cancer (CRPC), many of which further block the androgen axis [9]. Recent studies revealed that the frequency of AR-null CRPC is increasing, because of the application of more effective AR antagonists such as enzalutamide and abiraterone [10]. Since the effort of urologists for the patient in the end stage of this disease is limited, it is imperative for the scientists to progress effective biomarkers for very early detection and active target for clinical treatment.

Up to now, protein PSA (Prostate Specific Antigen) is the only biomarker used in clinical practice. Folk with high risks in PCa were screened out by measuring expression of PSA in the blood. The US Preventive Services Task Force (USPSTF) doubted the reliability and application of PSA by retrospective study [11]. For men aged from 55 to 69 years, the decision to undergo periodic PSA-based screening for PCa should be well assessed based on their particlular clinical characteristics like family history [12]. Therefore, it gives a few patients a limited potential profit of prognosis through screening PSA [13]. Many men will suffer potential harms of screening, including false-positive results that entail extra testing and even, invasive prostate biopsy, to separate them from the real patients; overdiagnosis and overtreatment; and it may arouse a lot of treatment complications, such as incontinence and erectile dysfunction, which wastes unnecessary time, influences the normal life and lowers the quality of life [14]. Clinicians should not screen men who do not express a preference for screening (C recommendation) [15-17]. The USPSTF recommends against PSA-based screening for PCa in men 70 years and older (D recommendation) $[11,18,19]$. As there is progressively amounts of argument and distrust about the specificity and sensitivity of PSA, it is essential for us to advance more dependable biomarkers for early screening of PCa.

Non-coding RNAs (ncRNAs) are a class of RNA molecules that lack protein-coding potential. Accumulating genomic and transcriptomic sequencing results have revealed that only small proportion of the human genome is transcribed into protein-coding mRNAs, whereas the majority of the genome is transcribed into ncRNAs [20, 21]. Amongst the classes of ncRNAs, long noncoding RNAs (lncRNAs) are a class of transcripts longer than 200 nucleotides with limited protein coding potential [22]. Unlike proteins, ncRNAs function cannot currently be inferred from sequence or structure, with the diversity of long ncRNAs described to date precluding simple generalizations [23]. LncRNAs regulate local proteincoding gene expression at the level of chromatin remodeling, transcriptional control and post-transcriptional processing, which suggests that RNA has continued to evolve and expand alongside proteins and DNA and indicate they have multiple functions in a wide range of biological processes, such as proliferation, apoptosis, or cell migration [24, 25]. Various of transcriptomics studies showed that some kind of IncRNA dysregulated in different cancers, including neuroblastoma, pancreatic ductal adenocarcinoma, lung cancer and other cancers through corresponding miRNAs [26-29]. Moreover, this abnormal phenomenon are also detected in circulating blood and/or urine [30-32]. LncRNA is a novel class of potential biomarkers and therapeutic targets for the treatment of cancer [33].

Nevertheless, the function of most lncRNAs is still unknown. A growing amount of evidence has showed that lncRNAs play a vital role in the progression of $\mathrm{PCa}$ [34]. Especially, the expression levels and potential roles of lncRNAs in $\mathrm{PCa}$ are needed to further investigated [35]. Herein, we combined our analysis of RNA-seq datasets, from 5 patient samples, including $\mathrm{PCa}$ and adjacent benign prostate tissue with the other investigation to exploit and corroborate differentially expressed lncRNA connected with $\mathrm{PCa}$. After we detected the dysregulated lncRNAs from transcriptome profiles, we validated these lncRNAs from RNA-seq with qRT-PCR using another 5 tumor specimens and 7 para-cancerous/benign contrasts from prostate biopsy.

\section{Material and method \\ Tissue samples}

A group of 5 pairs of $\mathrm{PCa}$ and matched non-tumor normal tissues were collected from Huashan Hospital, Fudan University. To deep confirm, another cohort of prostate tissues were obtained from prostate needle biopsies in Huashan Hospital, Fudan University. Our study was permitted by the ethics committee of Huashan Hospital, Fudan University (ethics approval no. 2011-009) and written informed consent was obtained from all patients. All tissue was histologically identified by pathological section. If diagnosed as prostate adenocarcinoma, the 
Gleason score, PSA value, TNM stage and recurrence were according to the NCCN guideline [36]. Otherwise, the tissues were recognized as normal contrast. A subset of patients had matched PCa tissues and normal tissues available for qPCR. The initial screening step (Table 1) was conducted with microarray chip assay. Another cohort screening information which was considered as the validation of the expanded clinical samples (Table 2) was listed with the qPCR.

\section{RNA extraction and purification}

Total RNA of tissue specimen was extracted and purified using mirVana ${ }^{\mathrm{TM}}$ miRNA Isolation Kit (Cat\#AM1561, Ambion, Austin, TX, US) following the manufacturer's instructions and checked for a RIN number to inspect RNA integration by an Agilent Bioanalyzer 2100 (Agilent technologies, Santa Clara, CA, US).

\section{RNA labeling}

rRNA was amplified and labeled by Low Input Quick Amp WT Labeling Kit (Cat.\# 5190-2943, Agilent technologies, Santa Clara, CA, US), following the manufacturer's instructions. Labeled cRNA were purified by RNeasy mini kit (Cat.\# 74,106, QIAGEN, GmBH, Germany).

\section{Array hybridization}

Each slide was hybridized with $1.65 \mu \mathrm{g}$ Cy3-labeled cRNA using Gene Expression Hybridization Kit (Cat.\# 5188-5242, Agilent technologies, Santa Clara, CA, US) in Hybridization Oven (Cat.\# G2545A, Agilent technologies, Santa Clara, CA, US), according to the manufacturer's instructions. After $17 \mathrm{~h}$ hybridization, slides were washed in staining dishes (Cat. \# 121, Thermo Shandon, Waltham, MA, US) with Gene Expression Wash Buffer Kit (Cat.\# 5188-5327, Agilent technologies, Santa Clara, CA, US), followed the manufacturer's instructions. Differentially expressed IncRNAs were analyzed with independent samples t-test. LncRNAs with $\geq 2.0$ fold-changes (FC) and $p<0.05$ were selected as lncRNAs with significant differential expression.

\section{Data acquisition}

Slides were scanned by Agilent Microarray Scanner (Cat\#G2565CA, Agilent technologies, Santa Clara, CA, US) with default settings, Dye channel: Green, Scan resolution $=3 \mu \mathrm{m}$, PMT 100\%, 20bit. Data were extracted

Table 1 The main clinical information of patients with PCA included in our study

\begin{tabular}{lllllll}
\hline NO & Gender & Age (Years) & Histological type & Initial total PSA & Gleason score & TNM stage \\
\hline 12 & Man & 64 & Adenocarcinoma & 9.39 & $3+4$ & T2cN0M0 \\
34 & Man & 50 & Adenocarcinoma & 15.84 & $4+3$ & T3bN0M0 \\
56 & Man & 62 & Adenocarcinoma & 14 & $4+3$ & T3bN0M1 \\
78 & Man & 54 & Adenocarcinoma & 9.13 & $4+3$ & T2cN0M0 \\
910 & Man & 62 & Adenocarcinoma & 54.66 & $5+4$ & T3bN1M1 \\
\hline
\end{tabular}

Table 2 The clinical characteristics of extended samples by prostate biopsy for qPCR included in our study

\begin{tabular}{|c|c|c|c|c|c|c|}
\hline NO & Gender & Age (years) & Histological type & Initial total PSA & Gleason score & $\begin{array}{l}\text { Proportion } \\
\text { of Cancer } \\
\text { tissue }\end{array}$ \\
\hline 001 & Man & 62 & Adenocarcinoma & 10.44 & $3+4$ & $80 \%$ \\
\hline 002 & Man & 51 & Adenocarcinoma & 8.08 & $4+5$ & $70 \%$ \\
\hline 003 & Man & 53 & Adenocarcinoma & 9.11 & $4+4$ & $30 \%$ \\
\hline 004 & Man & 54 & Adenocarcinoma & 8.48 & $3+3$ & $5 \%$ \\
\hline 005 & Man & 55 & Adenocarcinoma & 11.84 & $4+3$ & $60 \%$ \\
\hline 006 & Man & 63 & Normal tissue & 10.92 & / & / \\
\hline 007 & Man & 78 & Normal tissue & 9.46 & / & / \\
\hline 008 & Man & 50 & Normal tissue & 9.56 & / & / \\
\hline 009 & Man & 63 & Normal tissue & 12.71 & / & / \\
\hline 010 & Man & 72 & Normal tissue & 10.82 & / & / \\
\hline 011 & Man & 77 & Normal tissue & 8.33 & / & / \\
\hline 012 & Man & 58 & Normal tissue & 9.21 & / & / \\
\hline
\end{tabular}


with Feature Extraction software 10.7 (Agilent technologies, Santa Clara, CA, US). Raw data were normalized by Quantile algorithm, Limma packages in R.

\section{Bioinformatics analysis}

LncRNA targets identified with profiling data were subjected to Gene Ontology (GO) and Kyoto Encyclopedia of Genes and Genomes (KEGG) pathway analyses based on their correlated mRNAs using GO (https://www. geneongoloty.org/) and KOBAS software (KEGG Orthology-Based Annotation System, https://www.kegg.jp/), $[37,38]$. The differentially expressed lncRNAs-targeted miRNAs were sought and predicted by miRanda software (https://miranda.org.uk/) coupled with statistical analysis. The lncRNAs expression profile microarray chip assay, besides data and bioinformatics analysis were carried out by Shanghai Biotechnology Corporation (Shanghai, China).

\section{qPCR analysis}

Total RNA from another normal tissues (9 samples) and PCa tissues (7 samples) sustained by pathology after perineal prostate biopsy guided by ultrasound was prepared by Trizol Isolation Reagent (Invitrogen). Dimethylcarbinol, ethanol and trichloromethane were of analytic grade. DNase I, SYBR Green Realtime PCR Master Mix Plus and the ReverTra Ace qPCR RT Kit are from Toyobo Co. Japan. $2 \mu \mathrm{g}$ RNA was extracted from each sample was used for cDNA preparation. The reverse transcription kit steps are strictly followed to transcribe to cDNA. cDNA was used as template, and hGAPDH as internal parameter. The primer concentration was set as $0.4 \mu \mathrm{mol} / \mathrm{L}$. Three parallel samples were set for each sample, tested as $15 \mu \mathrm{l}$ system used for amplification. For qPCR solution, THUNDERBIRD SYBR qPCR Mix (Toyobo, Osaka, Japan) was utilized. qPCR was performed on the LightCycler 96 (Roche, Indianapolis, IN, USA) following the instruction. The reaction conditions of qPCR were: predenaturation at $95^{\circ} \mathrm{C}$ for $3 \mathrm{~min}$, denaturation at $95^{\circ} \mathrm{C}$ for $15 \mathrm{~s}$, annealing at $60^{\circ} \mathrm{C}$ for $15 \mathrm{~s}$, extension at $72{ }^{\circ} \mathrm{C}$ for $20 \mathrm{~s}$ and totally 40 cycles. Assay numbers got involved in the top 10 up-regulated and down-regulated expression of lncRNAs and GAPDH, respectively. The sequences of primer are listed in the Table 3. Differentiated gene expression was calculated by the comparative $\mathrm{Ct}$ method.

\section{The co-expression network of IncRNA-miRNA-mRNA}

Spearman correlation was calculated between the abundance of each lncRNA against each miRNA with the criteria of relative expression levels. Once the predicted pairs of lncRNA-miRNA relation were determined, and further filtered by comparison with the theoretical databases. The theoretical databases included ENCORI,
Table 3 The list of the primer sequence for the top 10 up-regulated and down-regulated IncRNAs

\begin{tabular}{|c|c|}
\hline The accession of IncRNA & The primer sequence \\
\hline hGAPDH-Q-F & TCAAGGCTGAGAACGGGAAG \\
\hline hGAPDH-Q-R & TCGCCCCACTTGATTTTGGA \\
\hline NR_125857-F & CCCATCCTCATTTGGTGCTG \\
\hline NR_125857-R & CAACAGACAACACGAGGCAG \\
\hline NR_015342-F & GAAGCACCTCGCATTTGTGG \\
\hline NR_015342-R & TTTCTCAAACCGCCTGATGC \\
\hline NR_109832-F & TCCGTCTCCTGCATGTCCTTGG \\
\hline NR_109832-R & ACCTTCACCCTCCAGCCACAG \\
\hline ENST00000412654-F & AGCATGGTCCCCAATGTAGC \\
\hline ENST00000412654-R & CCACCCATGAGGCGTAATCA \\
\hline Inc-AC110080.1-5:1-F & CCATCTCCTGCAAGTCTAGTCA \\
\hline Inc-AC110080.1-5:1-R & TGCCACTGAACCTATCTGGC \\
\hline ENST00000415820-F & GAGGGTAGATGGAGCATCGC \\
\hline ENST00000415820-R & TTCCAGTTCTTTGCTCCGCA \\
\hline ENST00000558010-F & TGCCCGTAATCCCTTTGTCC \\
\hline ENST00000558010-R & ATTTGGTGCCGTGTGCTAGA \\
\hline ENST00000365110-F & TTGCACGTTGTTGGAGCTTG \\
\hline ENST00000365110-R & AATTTGCCCCTCACGTAGCA \\
\hline NONHSAT072254-F & CAGGGCCAGTCAGAGTCTTTC \\
\hline NONHSAT072254-R & CCACTGAACCTGTCTGGGATG \\
\hline NONHSAT072236-F & CAGGGCCAGTCAGAGTCTTTC \\
\hline NONHSAT072236-R & CCACTGAACCTGTCTGGGATG \\
\hline ENST00000424251-F & TGGCATGAGCAAACTTGGGC \\
\hline ENST00000424251-R & CAGTGCCAATAACGGCCACA \\
\hline Inc-TACC2-3:1-F & ACGCCTGCATCTTCACAAAG \\
\hline Inc-TACC2-3:1-R & TCAAAGCTACACAATGCGGG \\
\hline NR_125859-F & TTTGCCCATAAGTCTCCCTGG \\
\hline$N R \_125859-R$ & TTCCAAGCCAGCGTTTTCAC \\
\hline NONHSAT136589-F & TGCTGGCTGCTCTGAACTAAA \\
\hline NONHSAT136589-R & TCCAGCTTTTAGGCACACACA \\
\hline Inc-CHST2-2:3-F & TGCAGACAAGTGTGTATGAGT \\
\hline Inc-CHST2-2:3-R & CTGTCTGCTAACAAAGGGTTCA \\
\hline Inc-PDCD1 1-5:1-F & AATCCCATCAGGCGTAGGG \\
\hline Inc-PDCD1 1-5:1-R & GCAGAAATCACACCCAGGTTC \\
\hline Inc-PTEN-11:1-F & TGCCAGTCTCTAGGTCCCTG \\
\hline Inc-PTEN-11:1-R & AGACGCCAGGCTCCCAA \\
\hline Inc-MID1-4:1-F & CAGAGCAAGGCACCCACTAA \\
\hline Inc-MID1-4:1-R & CCCACGACTGCTCCAAAGTA \\
\hline Inc-C19orf73-1:1-F & ACTGCGACACAGCGGTA \\
\hline Inc-C19orf73-1:1-R & GGAGCACGTTTATTCAGAGAAAT \\
\hline Inc-MYL2-4:1-F & TATTGTTCCTGGGCTGCAGA \\
\hline Inc-MYL2-4:1- R & GGAGAACACGTTGGAGTTGG \\
\hline
\end{tabular}

* $-\mathrm{F}$ presented the forward primer while $-\mathrm{R}$ presented the reverse primer

lncBase, miRcode for lncRNA-miRNA relations and miRcode, ENCORI, TarBase, miRTarBase, miRDB, miRanda, miRecords for miRNA-mRNA relations. For Agilent chip GPL22120, adopt multiple IDs from different sources, 
should be correspond to one unique ID, and we map the all IDs in GPL22120 to RNA Central (https://www.rnace ntral.org/, v14) [39]. All the lncRNA ID listed in figure were started by "URS" which was the acronym of Unique RNA Sequence and combined with 10 numbers and/ or English letters.

\section{Survival Curve Analysis}

We used the GEPIA (Gene Expression Profiling Interactive Analysis, https://gepia.cancer-pku.cn/) as tool to search for the survival curve of the top 10 upregulated and downregulated lncRNAs original gene [40].

\section{Statistical analysis}

All data are shown as mean \pm standard deviation (SD). Statistical significance was determined using Student's t-test by SPSS 13.0 and Graphpad Prism 5. $p<0.05$ was considered statistically significant.

\section{Result}

LncRNAs expression profiles in PCa

The microarray screening identified 68,424 lncRNAs in $\mathrm{PCa}$, non-PCa or both tissues. As illustrated in Fig. 1, totally, 817 lncRNAs were differentially expressed between $\mathrm{PCa}$ tumor and paracancerous tissues $(\mathrm{FC} \geq 2.0$ and $\mathrm{p}<0.05)$ : among which 422 were upregulated, and the remaining 395 were downregulated in $\mathrm{PCa}$ tissues. The magnitude of FC was the highest for NR_125857 for upregulated IncRNAs $(F C=59.27658, p=0.00128)$ while it was the lowest for lnc-MYL2-4:1 in downregulated lncRNAs $(\mathrm{FC}=0.00141, \mathrm{p}=0.01909)$. Hierarchical clustering (Fig. 2D), volcano plot (Fig. 3), and scatter plots (Fig. 3) shown that the different expression profiles of lncRNAs between $\mathrm{PCa}$ and non-PCa tissues were diverse. The top each twenty up- and down-regulated lncRNAs were listed in Table 4.

\section{Bioinformatics analysis of differential expressed IncRNAs}

Top each twenty up- and down-regulated lncRNAs and corresponding gene information of lncRNAs were shown in Table 4. Moreover, each Top 30 enrichments about GO and KEGG analyses suggested that these differentially expression lncRNAs were relevant to several vital physiological processes, such as cardiac muscle hypertrophy, muscle hypertrophy, neural precursor cell proliferation,

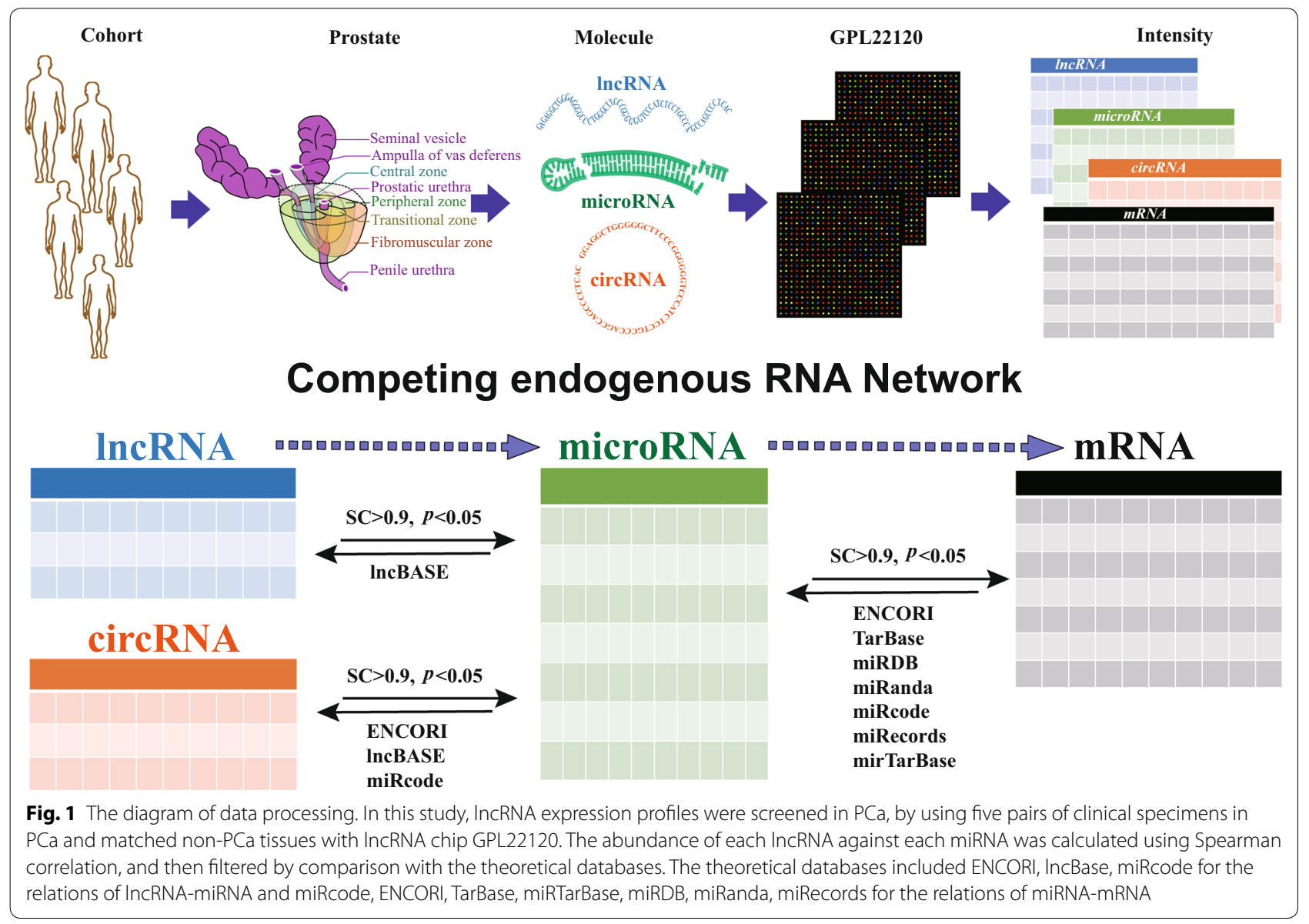




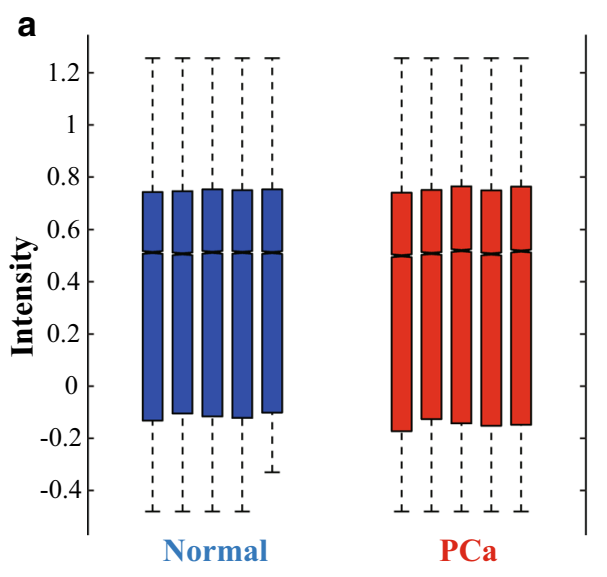

b
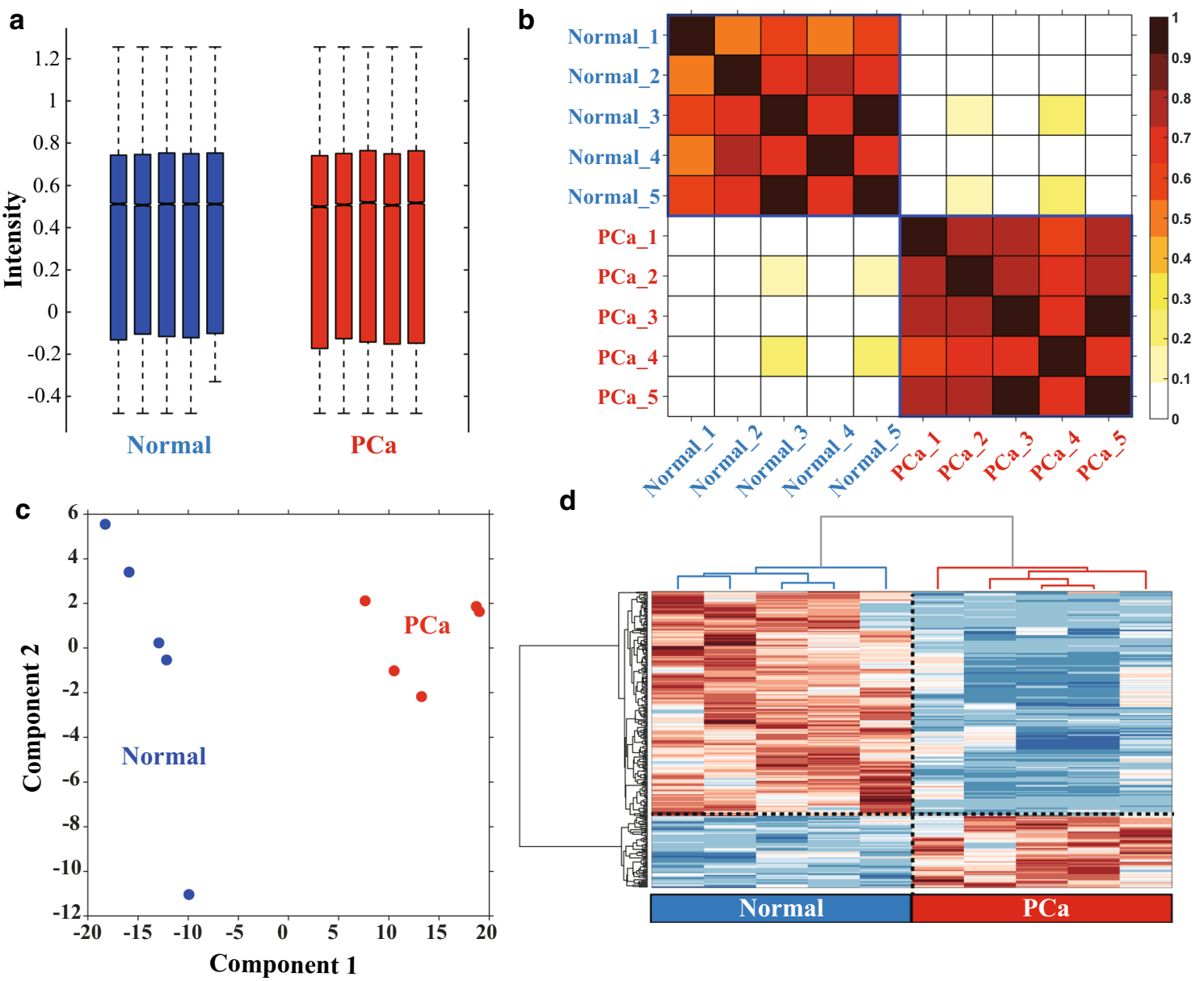

Fig. 2 Global view of all IncRNAs expression in PCa tissues compared to paired non-PCa tissues. a Boxplot. The medians between samples were roughly flat, and the ranges of expressions were similar. $\mathbf{b}$ Sample correlation matrix. The correlation coefficient within the groups was significantly higher than that between the groups, which indicated the larger differences between PCa tissues and paired non-PCa tissues. c Principal component analysis. The difference between normal and tumor was large in the first principal component, but slightly in the second principal component, which showed there was a big difference between the samples. $\mathbf{d}$ Hierarchy Clustering Analysis. Repeated samples are clustered together, indicating the repeatability of samples and the differences between samples. The black dotted line divides IncRNAs into two categories: above the line, it presented the part of high expression in non-PCa tissues and low expression in PCa, and below the line, it presented the part of high expression in PCa and low expression in non-PCa tissues. Overall, through a variety of global analysis, we concluded that our tissue samples used in our study presented good reproducibility and the large differences between groups.

establishment or maintenance of cell polarity, cardiac muscle tissue development, striated muscle cell development, muscle cell development, actin binding, and postsynaptic membrane. Intriguingly, most of them are associated with the muscle tissue development, including cardiac muscle and striated muscle, which may hint the reorganization of the excellular matrix on behalf of the smooth muscle surrounding the PCa. Moreover, the upregulation of the neuron formation shows the nerve paracrine factor involving in the tumorigenesis. Except for the famous pathways, such as TGF- $\beta$, Wnt, MARK and mTOR that have been proven to be closely correlated to proliferation, invasion and metastasis in $\mathrm{PCa}$, astonishingly, the pathway of aldosterone-regulated sodium reabsorption, dilated cardiomyopathy, hypertrophic cardiomyopathy, pathogenic Escherichia coli infection and vascular smooth muscle contraction also implies the revegetation of smooth muscle may interfere with the microenvironment of PCa. Additionally, the pathogenic Escherichia coli infection may link to the common urinary disease, prostatitis, which also causes the tissue recovery (Fig. 4).

\section{Validation of qPCR}

The outcome of qPCR showed significant statistic differences in NR_125857, NR_015342, 

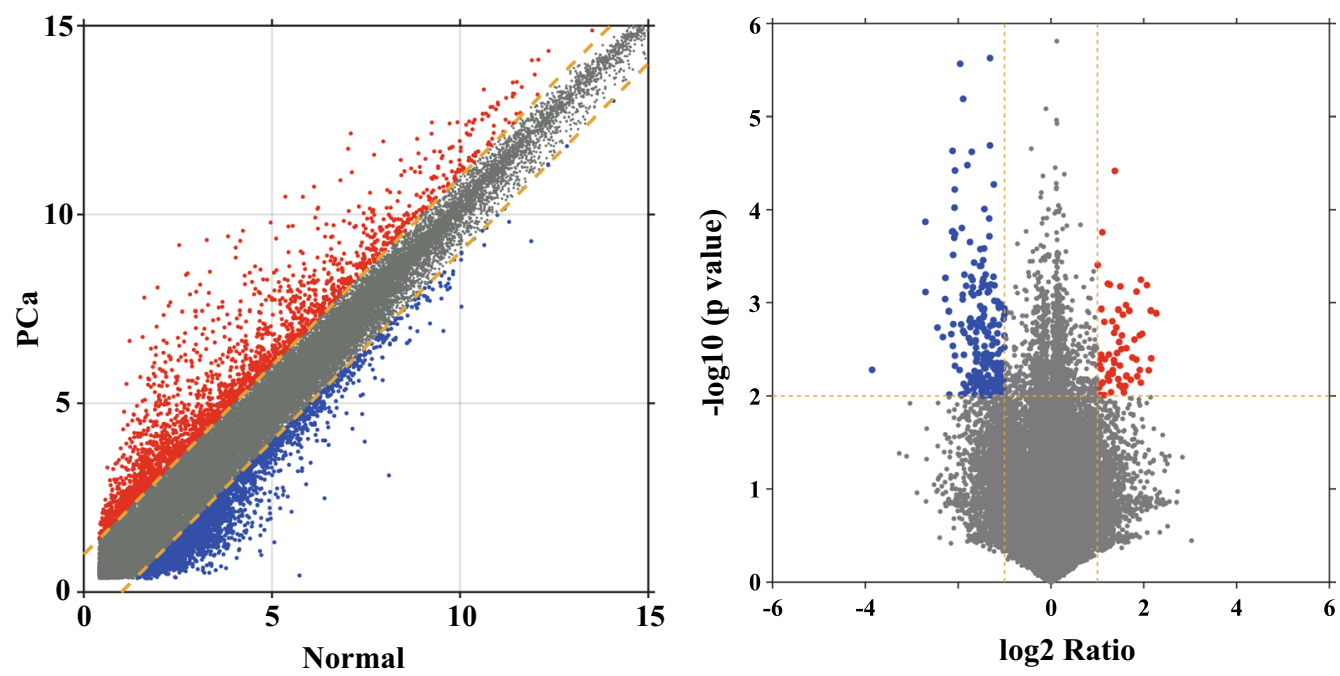

Fig. 3 Selection of differentially expressed IncRNAs. The scatter plots and volcano plots exhibited the differentially expressed IncRNAs in PCa tissues compared to paired non-PCa tissues. The left figure presented the scatter plots while the right figure presented the volcano plots

NR 109832, ENST00000412654, lnc-AC110080.1-5:1, ENST00000415820, ENST00000558010 $\quad(p<0.05)$ in PCa tissues $(\mathrm{n}=5)$ compared to normal prostate tissues $(n=7)$ while there was no statistic difference of all the top ten downregulated lncRNA expression (Fig. 5a, b). These results indicated that the expression of NR_125857, NR_015342, NR_109832, ENST00000412654, lnc-AC110080.1-5:1, ENST00000415820, ENST00000558010 were up-regulated in $\mathrm{PCa}$ and it revealed whether the downregulation of ENST00000424251, lnc-TACC2-3:1, NR_125859, NONHSAT136589, Inc-CHST2-2:3,lnc-PDCD115:1,lnc-PTEN-11:1, lnc-MID1-4:1, lnc-C19orf73-1:1, lncMYL2-4:1 was still doubted. Compared with the original outcomes of RNA-seq array, the relative expression of qPCR in the additional samples showed consistency in figure (Fig. 5C).

\section{Survival analysis of differential expressed IncRNAs}

As the top seven upregulated lncRNAs in our study revealed the coherence of bioinformatics analysis and qPCR analysis, we further analyzed their survival curves of original gene in PCa by the tool of GEPIA (https:// gepia.cancer-pku.cn/) (Fig. 6). Higher expression of prostate-specific DD3(PCa3) in patients of PCa showed lower survival rate after about 80 months while the higher expression of PCa associated transcript-14 (PCAT14) demonstrated higher survival rate since approximately 60 months. The high expression of AP001610.9 led to a dramatic decline of survival rate after 110 months despite the phenomenon that it revealed moderately higher survival rate from the 80 th to 110 th month. Moreover, differentiated expression of RP11-279F6.2 showed a subtle difference that the high expression would result in lower survival rate in the duration of 80th and 105th month. Nevertheless, there was no recorded data of NR_125857, which was the most upregulated lncRNA in our study.

\section{The co-expression network of IncRNA-miRNA-mRNA}

To supplementary achieve perceptions of the lncRNAs' biological functions in the complex biological processes and cellular regulation, the IncRNA-miRNA-mRNA coexpression network was constructed to investigate the potential interaction between miRNAs, mRNAs and lncRNAs. As shown in the Fig. 7, the co-expression network of lncRNA-miRNA-mRNA included 20 nodes of miRNAs and 84 connections consisting of various lncRNAs and mRNAs. Among the 17 networks, one of the most known co-expression networks was miR-17-5p because it had been proven that miR-17-5p repressed metallopeptidase inhibitor 3 expression in $\mathrm{PCa}$ while in this study we found the network of miR-17-5p also got involved in the gene EIF3H, HELLS and DNAL1, which was regulated by the same lncRNA URS000048C392 (also named ENST00000555037.1) [41]. With one edge networks like URS00008B6496(ENST00000547292.1), UR S 00000 B 8 A F 9 (EN S T 00000482003.1 ), URS0000EEB1F2(ENST00000436764) and URS00007CEE5E(lnc-DHX38-3:6), it should be simple to confirm their roles in $\mathrm{PCa}$ by further experiment. Some complicated networks like URS00008C2FEF(ENST00000591956), URS00008BBA94(ENST00000452731) 


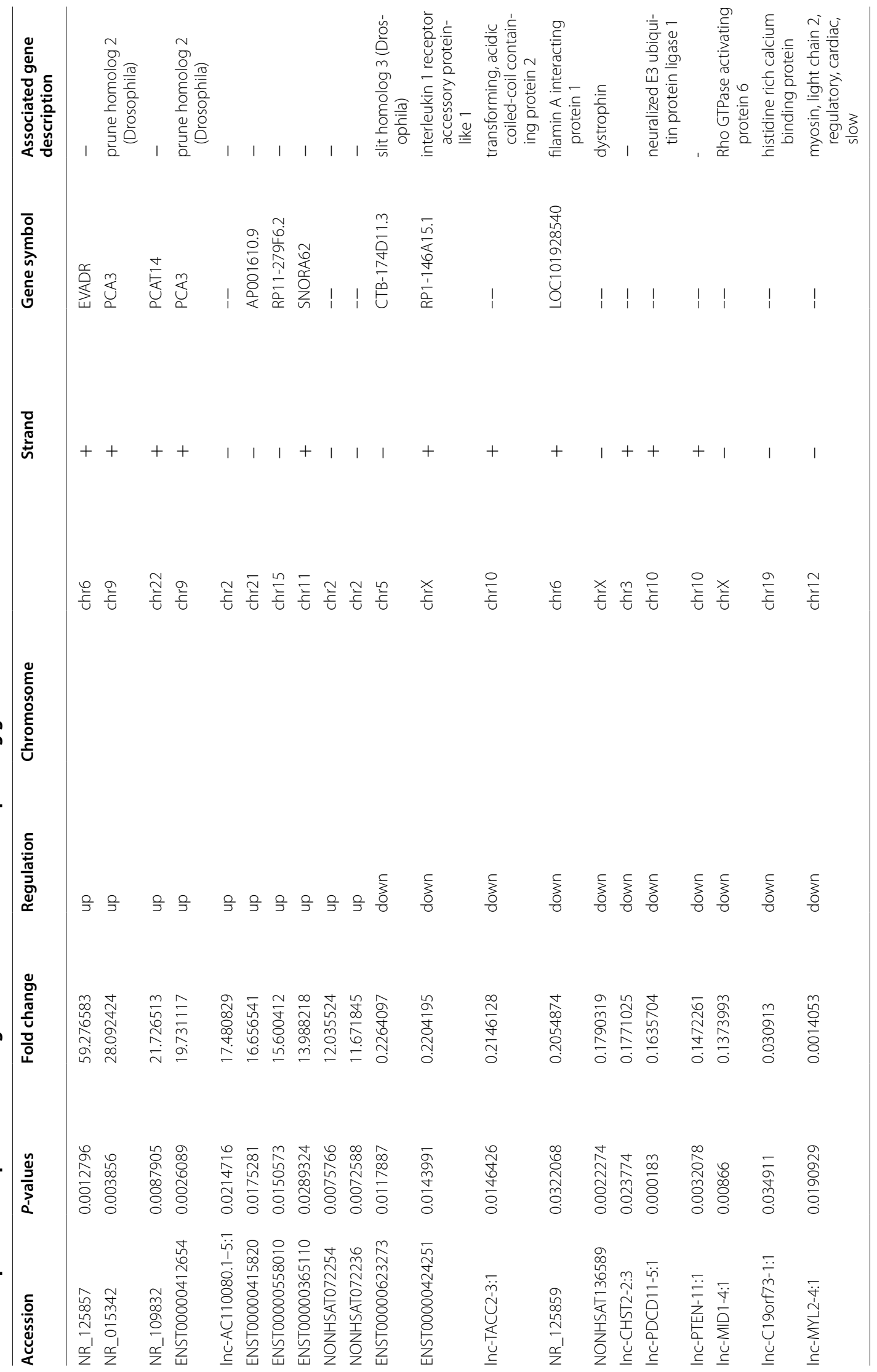




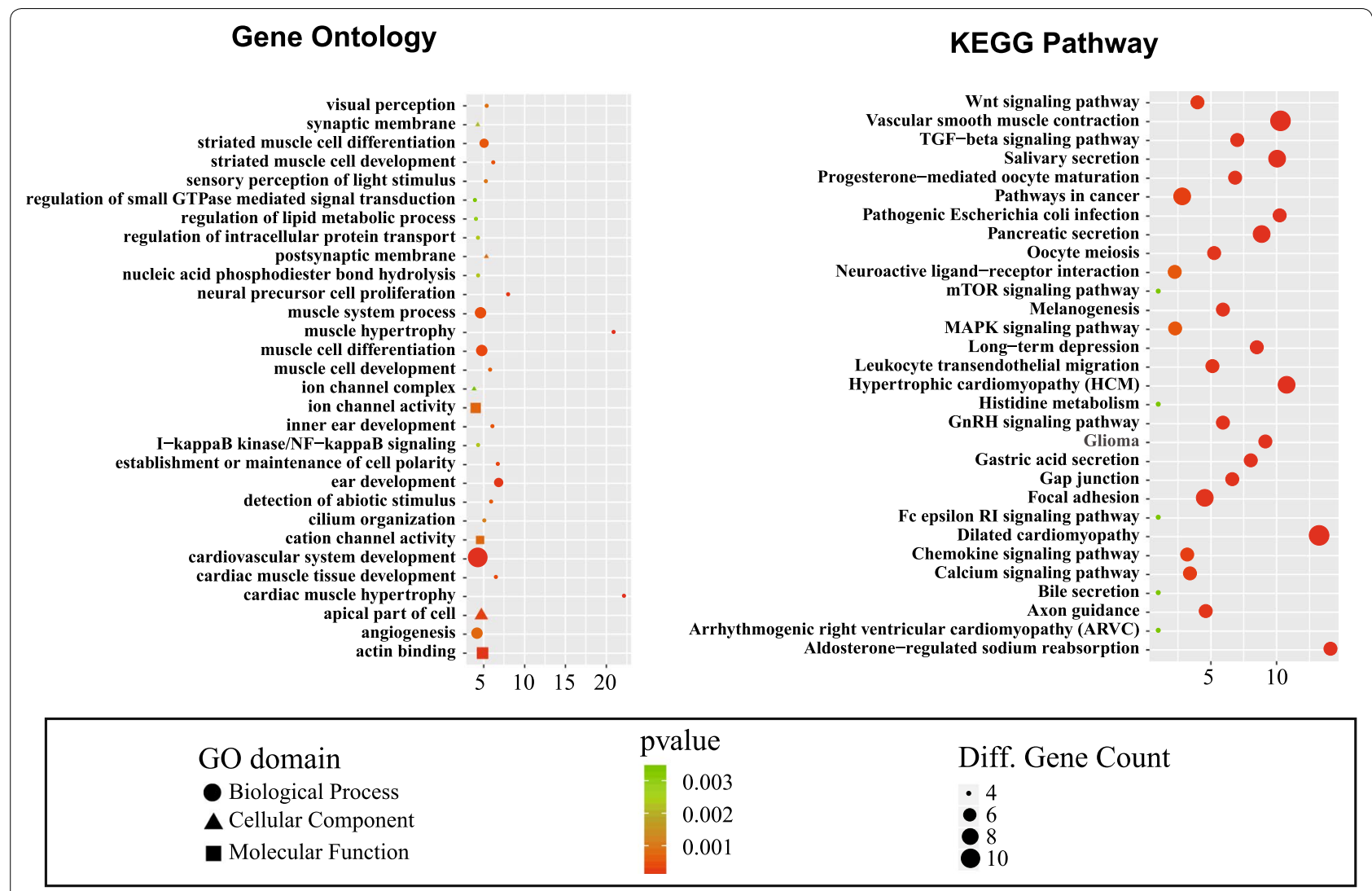

Fig. 4 Results of Gene Ontology and KEGG pathway analysis. a Top 30 classes of GO enrichment terms. b Top 30 classes of KEGG pathway enrichment terms

URS00009BE037(ENST00000492250) were associated with two diverse miRNA signal pathways, which indicated their might have different influence on PCa. URS00005D043E(ENST00000464382), URS000046AFA0(ENST00000534169) and UR S 0000 E F 6 B D 5 ( E N S T 000000435802 ) were connected to the same miR-375, and URS0000DB7AD5(ENST00000580175) and URS000032BFFB(ENST00000558749) were affected by miR-582-5p in the meanwhile. Although with several edges in mRNAs, the rest of IncRNA and miRNAs had the relationship of one-one correspondence. As demonstrated, those lncRNAs, miRNAs and mRNAs were vastly linked as the key hub of the co-expression network, which implied their vitally potential impact on lncRNAs in the progress of regulating particularly target genes in PCa.

\section{Discussion}

We noticed that NR_125857, related to the gene EVADR, ranked the first line of upregulation in our database. EVADR is the written abbreviation of Endogenous retroViral-associated ADenocarcinoma RNA (EVADR), by analyzing RNA-seq data derived from colorectal tumors and matched normal control tissues [42]. This lncRNA demonstrated nominal to low expression in normal tissue, but is significantly upregulated in cancer, particularly in colon, rectal, lung, stomach and pancreas adenocarcinomas. It was reported the EVADR lncRNA determined the promoter activity of the MER48 long terminal repeat (LTR) in vitro, mapped the genome-wide MER48 LTR expression [42]. Regardless of a biological function, the specificity of EVADR activation in adenocarcinomas coupled with the poorer survival probability that tracks with elevated EVADR expression suggested that further characterization of EVADR as a candidate adenocarcinoma biomarker is warranted [42]. Nevertheless, the original article did not mention any details about the EVADR in PCa. In our study, it was totally clear that the expression of NR_125857 is up-regulated in PCa by RNA-seq and qPCR (Fig. 5). Since it was described as the highest upregulated lncRNA in our research, it seemed to be a promising candidate in the further $\mathrm{PCa}$ research, for, without any doubt, $\mathrm{PCa}$ is also a kind of adenocarcinoma. Because the few investigations in this lncRNA, the coexpression network in this study had not been involved 

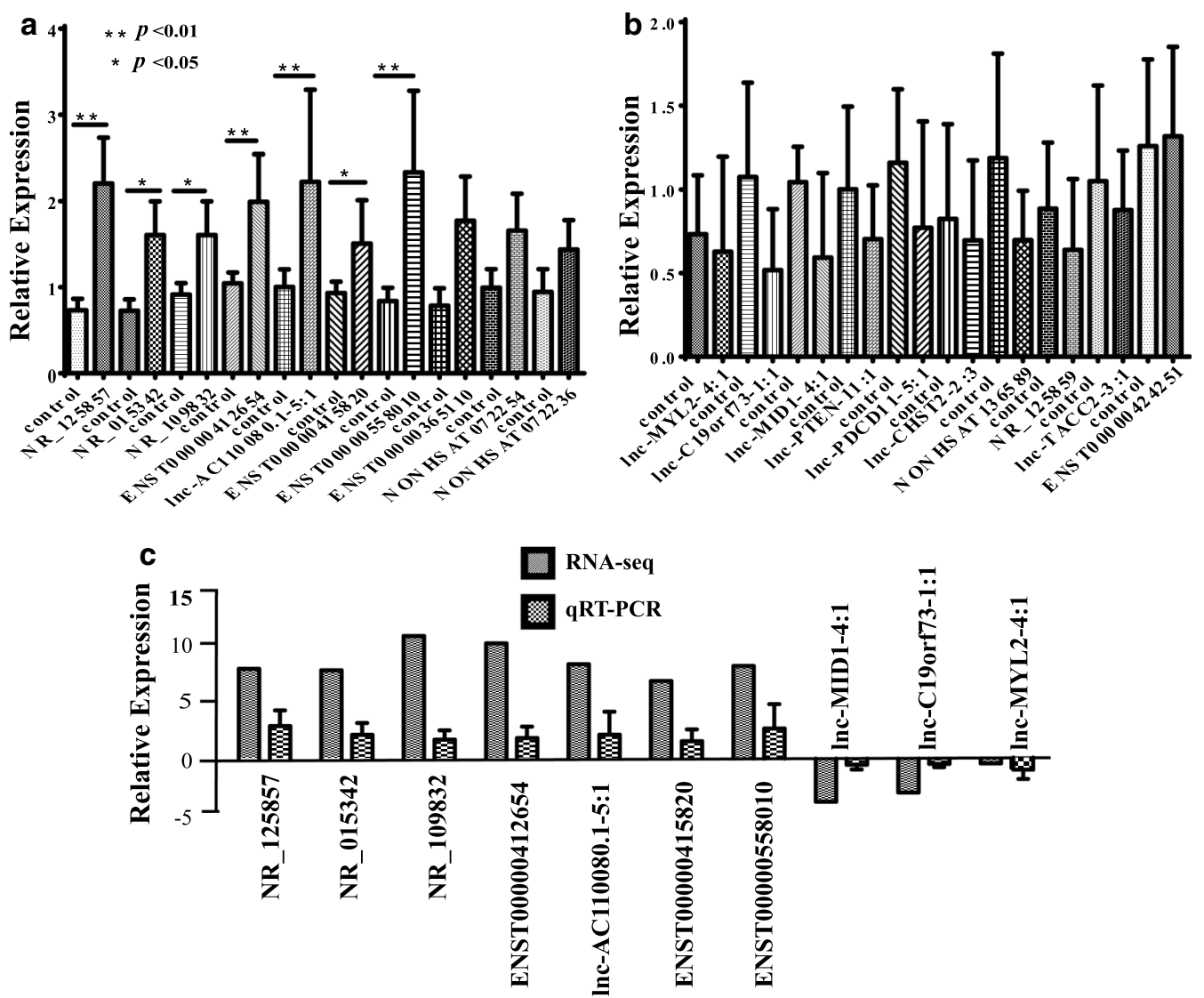

Fig. 5 The outcomes of subsequent verification tests by qPCR. a The relative expression of top ten upregulated IncRNAs in qPCR. There were significant statistic differences in NR_125857, NR_015342, NR_109832, ENST00000412654, Inc-AC110080.1-5:1, ENST00000415820, ENST00000558010 $(p<0.05)$. b The relative expression of top ten downregulated IncRNAs in qPCR. There was no significant statistic difference between them ( $p>0.05$ ), which may be due to the small sample size. c Confirmation of the expression patterns of IncRNAs by comparing the results of qRT-PCR and original array outcomes of RNA-seq. Top 7 up-regulated IncRNAs and top 3 down-regulated IncRNAs

in. The mechanism mediated by the high expression of NR_125857 in PCa requires further cavernous research and clinical following-up.

In the top five of the upregulation in lncRNA, NR_015342 and ENST00000412654 are associated with the PCA3, accounting for a large proportion. PCA3 was located on chromosome 9q21-22 [43]. PCA3, as one of the earliest identified lncRNAs, is an accepted diagnostic urinary biomarker for PCa [44]. Highly overexpression of PCA3 in PCa tissue was found to be a potential non-invasively prediction of prostate biopsy which might be a promising biomarker in clinical diagnosis $[45,46]$. In our verification test, we found the consistence of both NR_015342 and ENST00000412654 (Fig. 5). The survival curve also revealed the potential capability of prognostic prediction (Fig. 6a).

Ranking at the third up-regulation of genes, NR_109832 suggests the gene PCAT14 also play an important role in PCa tumorigenesis. PCAT14 is an AR-regulated transcript while PCAT14 is highly expressed in low grade disease and loss of PCAT14 predicts for disease aggressiveness and recurrence, and its overexpression suppresses invasion of PCa cells $[47,48]$. PCAT14 lower expression is significantly prognostic for multiple clinical endpoints supporting its significance for predicting metastatic disease that could be used to improve patient management [49]. The outcome of confirmation experiment exhibited the unanimous trend (Figs. 5c, 7b).

The sixth up-regulated gene symbol is related with AP001610.9, and ENST00000415820 may links to TMPRSS2. TMPRSS2, also named as PP9284 or PRSS10, is transmembrane serine protease 2 , which is a member of the membrane-anchored serine proteases family [50]. It has been figured out that TMPRSS2 mediates a proteolytic cascade regulated by androgen signaling, which promotes the progression, invasion, and metastasis of PCa cells by activating the matriptase and disordering the extracellular matrix [51, 52]. TMPRSS2 

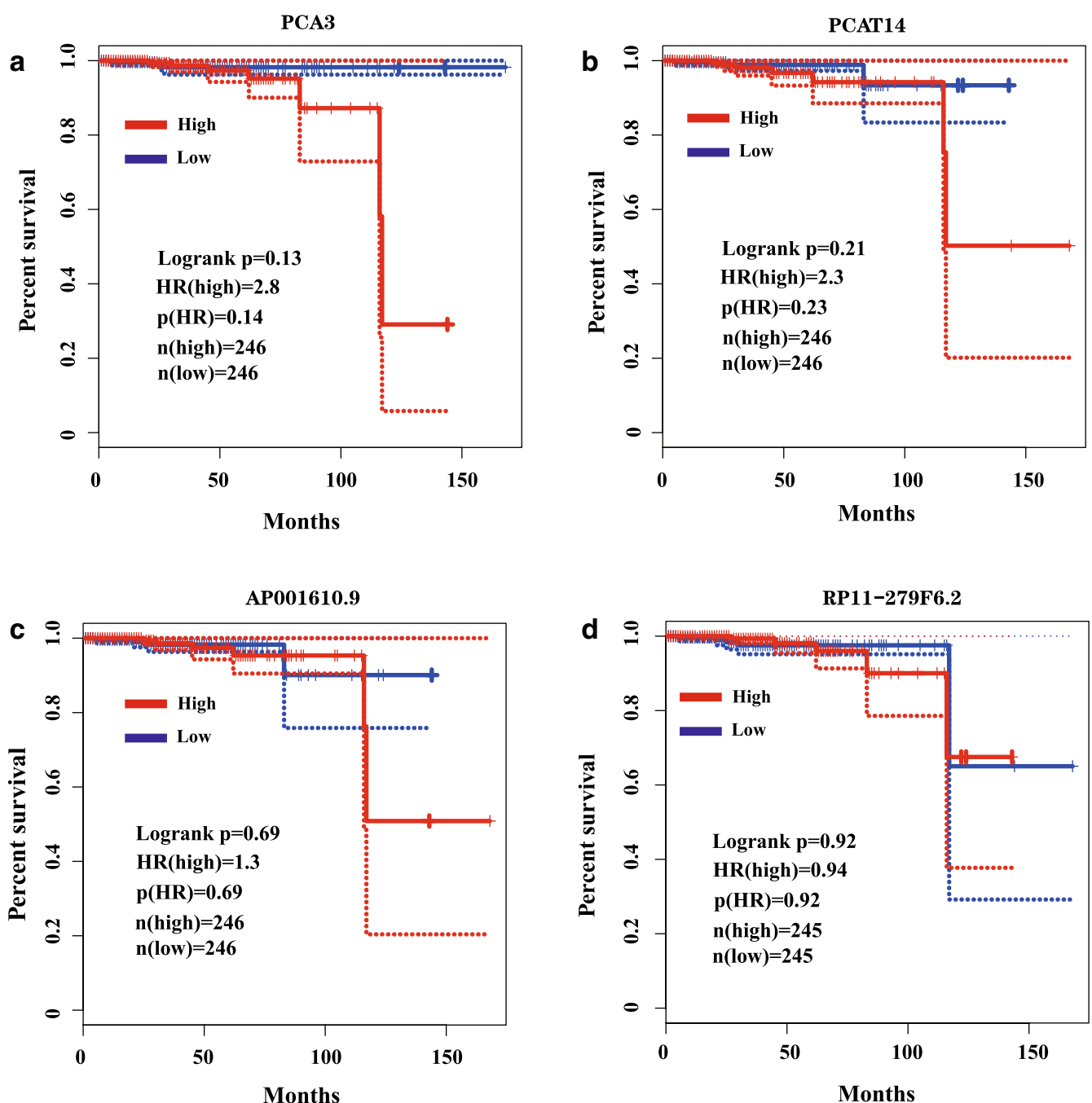

Fig. 6 The results of survival curve analysis by GEPIA. a The survival curve analysis of PCA3. $\mathbf{b}$ The survival curve analysis of PCAT4. c The survival curve analysis of AP001610.9. (d) The survival curve analysis of RP11-279F6.2. "RP11-279F6.2 is the corresponding gene symbol of ENST00000558010 (Table 4)

mainly affects degradation of extracellular matrix nidogen-1 and laminin $\beta 1$ [51]. Therefore, it indicates an innovative approach for targeting these two proteases in treatment development, and the intimate connection between tumor cells and extracellular matrix in the PCa. In our survival curve analysis, the high expression of AP001610.9 led to high hazard ratio after approximately 100 months (Fig. 6c). The relationship between ENST00000415820 and TMPRSS2 would be our interests for research.

The lowest down-regulation lncRNA is the anonymous lnc-MYL2-4:1. In our study, it suggests this lncRNA is interrelated to myosins, which are a large and diverse family of molecular motors important for cell migration and motility [53]. In PCa, Myo1b, Myo6, Myo9b, Myo10, and Myo18a were expressed at higher levels in high metastatic potential cells, and especially Myo1b and Myo10 were expressed at higher levels in metastatic tumors [5456]. Changes in expression of several myosin isoforms may contribute to metastasis in PCa [54]. The GO analysis in our study showed the enrichment in the muscle system process, muscle hypertrophy and muscle development while KEGG pathway research also revealed vascular smooth muscle contraction got involved in $\mathrm{PCa}$ specimens (Fig. 4). Though the outcome of qPCR in this study was no significant different in PCa tissues and normal tissues, the exact interaction between our candidate lncRNA and myosin is still needed to research.

The second down-regulation lncRNA lnc-C19orf73-1:1 is related to histidine rich calcium binding protein 


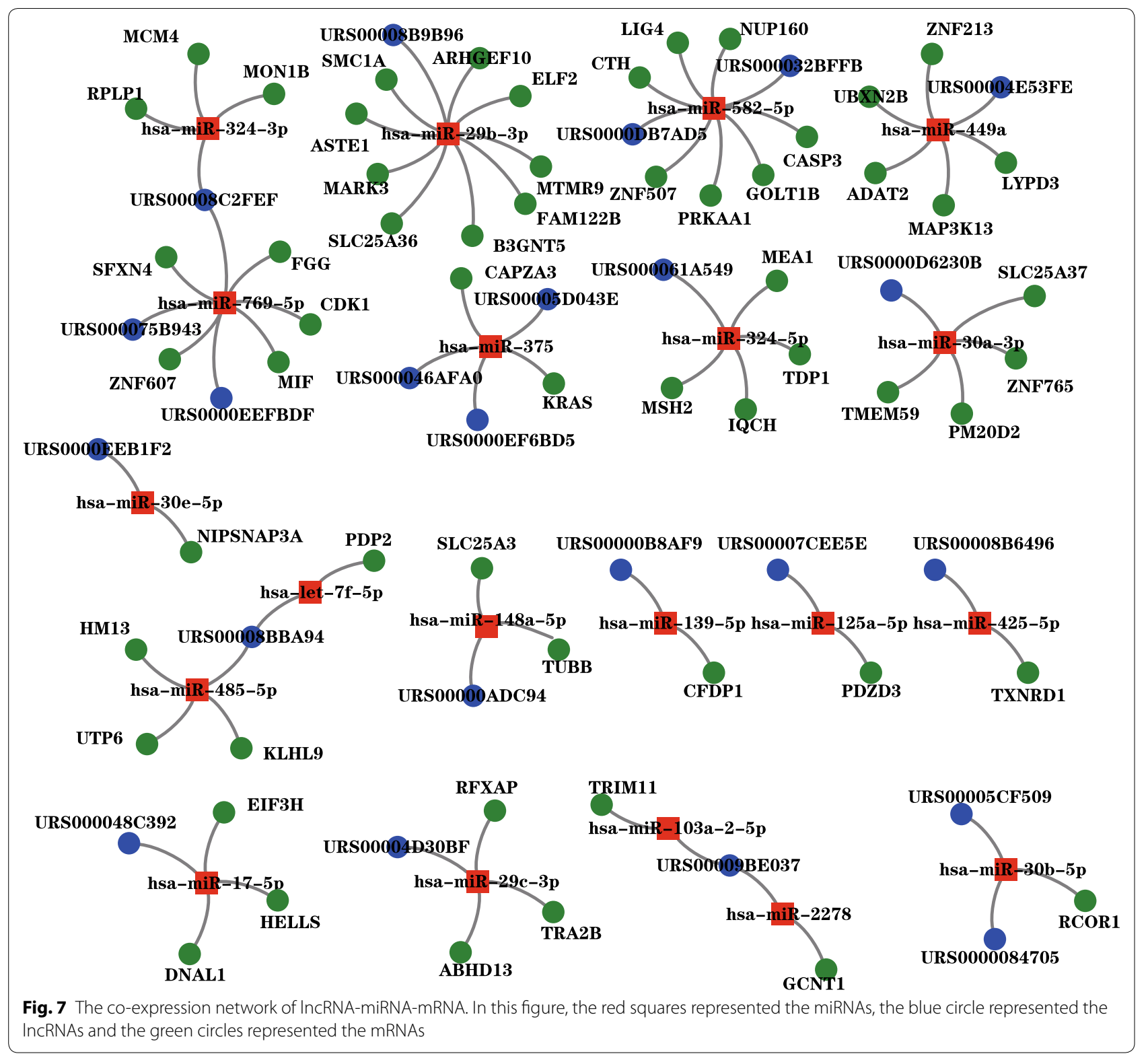

(HRC). The HRC is a novel regulator of sarcoplasmic reticulum (SR) $\mathrm{Ca}^{2+}$-uptake, storage and release, so the $\mathrm{HRC}$ plays a pivotal role in $\mathrm{Ca}^{2+}$-homeostasis. 2 Calcium $\left(\mathrm{Ca}^{2+}\right)$ is an essential intracellular signaling molecule involved in the regulation of cancer progression, including cell proliferation, apoptosis, invasion and migration $[57,58]$. Our KEGG research demonstrated the Calcium signal pathway referred to PCa (Fig. 4). It has been proved that HRC promotes growth of hepatocellular carcinoma in vitro and in vivo [59]. Furthermore, HRC also plays a significant role in myocyte differentiation and in anti-apoptotic cardioprotection against ischemia/ reperfusion induced cardiac injury [60]. Intriguingly, the cardiovascular system development, cardiac muscle development, and cardiac muscle hypertrophy were displayed in GO analysis(Fig. 4). We speculated the whole field of muscle, as the part of extracellular matrix component, may make a profound effect on the biological property of PCa (Additional file 1: Table S1).

Lnc-MID1-4:1, located on the chromosome $\mathrm{X}$, is associated with Rho GTPase activating protein 6. Rho GTPases have been figured out to be critical signal transducers, which mediate growth factor-induced changes to the actin cytoskeleton and activating the phagocyte NADPH oxidase [61]. The deleted in liver cancer 1 (DLC1) gene encodes a GTPase activating protein that acts as 
a negative regulator of the Rho family of small GTPases, and DLC- 1 is assumed as a bona fide tumor suppressor gene in different types of human cancer [62, 63]. Combined the results of our GO analysis, we found the abnormality actin binding in $\mathrm{PCa}$, which hinted that the down-regulation of Lnc-MID1-4:1 might influence on the particularly cellular functions in PCa.

In our analysis, there are ten qualified samples, so our study still has boundedness in the number of samples. To highlight the coherence of our outcomes and practical issues and value, we further extended the clinical samples for qPCR and drew the survival curves of meaningful genes of lncRNAs after the confirmation of qPCR. The top seven upregulation lncRNAs, like NR_125857, NR_015342, NR_109832, ENST00000412654, lnc-AC110080.1-5:1, ENST00000415820 and ENST00000558010 are hopeful research candidates for extra investigation. The present study of IncRNAs in PCa tissues is a proof-of-principle that lncRNAs have a possible character in $\mathrm{PCa}$ formation and progression. As demonstrated in the tables, there are so many lncRNAs has the relationship with $\mathrm{PCa}$, so lots of verification test are need to be completed. Since both PCA3 and PCAT14 have been thoroughly studied, so they partly played a special role on the ensuring our research credibility and providing us the reliable reference. With the deep research, the potential mechanism of IncRNA will be disclosed stepwise, which provides new breakthroughs in the early diagnosis, prognosis, and therapy targets of PCa.

\section{Conclusion}

Our study mapped a novel landscape of lncRNA differential expression between $\mathrm{PCa}$ and benign prostate tissues. Especially, we first found NR_125857 expression in human PCa tissues was the most up-regulated lncRNA. Moreover, we constructed a co-expression network of lncRNA-miRNA-mRNA for further study of mechanism in $\mathrm{PCa}$. As a promising candidate, further studies are needed to investigate to figure out the mechanisms in PCa.

\section{Supplementary information}

Supplementary information accompanies this paper at https://doi. org/10.1186/s12935-020-01615-y.

Additional file 1: Table S1. Top each 20 up- and down-regulated IncRNAs and corresponding gene information of IncRNAs.

\section{Abbreviations}

PCa: Prostate cancer; AR: Androgen receptor; PSA: Prostate specific antigen; CRPC: Castration-resistant prostate cancer; ncRNAs: Non-coding RNAs; tRNAs: Transfer RNAs; rRNAs: Ribosomal RNAs; miRNAs: MicroRNAs; snoRNAs: Small nucleolar RNAs; sRNAs: Small nuclear RNAs; IncRNAs: Long non-coding RNAs;
GO: Gene ontology; KEGG: Kyoto Encyclopedia of Genes and Genomes; PCA3: Prostate-specific Dd3; PCAT14: Prostate Cancer Associated Transcript-14; USPSTF: Us preventive services task force; EVADR: Endogenous retroViral-Associated ADenocarcinoma RNA; LTR: Long terminal repeat; GTPases: Guanosine triphosphatases; TMPRSS2: Transmembrane Serine Protease 2; SNORA62: Small Nucleolar RNA, H/Aca Box 62; HRC: Histidine rich calcium binding protein; DLC-1: Deleted in liver cancer 1.

\section{Acknowledgements}

We are grateful for the guidance of Professor Guowei Xia.

\section{Authors' contributions}

FZ, YZ, GWX and SCY conceived and designed the experiments. YYM and CYS performed the experiments. YYM, SYG, YJG and QFH analyzed the data. YZ and FZ contributed analysis tools. SYG and YYM wrote the paper. XJZ, CYS, $Y Z$ and GWX revised the manuscript. All authors read and approved the final manuscript.

\section{Funding}

This study was supported by grants from the National Key Research and Development Program of China (2018YFC0910700, 2016YFB0201702) and the National Natural Science Foundation of China (no. 81372316, 81802576).

\section{Availability of data and materials}

The datasets used and analyzed in the current study are available from the corresponding author on reasonable request.

\section{Ethics approval and consent to participate}

This study was approved by the Ethics Committee of Huashan Hospital, Fudan University. All enrolled patients signed written informed consent prior to sample collection. Ethics approval no. 2011-009.

\section{Consent for publication}

Not applicable.

\section{Competing interests}

The authors declare that they have no competing interests.

\section{Author details}

${ }^{1}$ Department of Urology, Huashan Hospital, Fudan University, 12 Central Urumqi Rd, Shanghai 200040, P. R. China. ${ }^{2}$ Department of Urology, Affiliated Hospital of Jiangnan University, Hefeng Rd, Wuxi 214000, PR China. ${ }^{3}$ Department of Clinical Immunology, Shanghai Center for Clinical Laboratory, 528 Hongshan Rd, Shanghai 200126, P. R. China. ${ }^{4}$ Department of Urology, Jing'an District Central Hospital, Fudan University, 259 Xikang Rd, Shanghai 200040, P. R. China. ${ }^{5}$ Department of Systems Biology for Medicine, and Institutes of Biomedical Sciences, Shanghai Medical College, Fudan University, 130 Dongan Rd, Shanghai, P. R. China.

Received: 17 June 2020 Accepted: 20 October 2020

Published online: 01 November 2020

\section{References}

1. Siegel RL, Miller KD, Jemal A. Cancer statistics, 2020. CA Cancer J Clin. 2020;70(1):7-30.

2. Torre LA, Bray F, Siegel RL, Ferlay J, Lortet-Tieulent J, Jemal A. Global cancer statistics, 2012. CA Cancer J Clin. 2015;65(2):87-108.

3. Feng RM, Zong YN, Cao SM, Xu RH. Current cancer situation in China: good or bad news from the 2018 Global Cancer Statistics? Cancer Commun. 2019;39(1):22.

4. Rebbeck TR. Prostate cancer genetics: variation by race, ethnicity, and geography. Semin Radiat Oncol. 2017;27(1):3-10.

5. Dobbs RW, Malhotra NR, Greenwald DT, Wang AY, Prins GS, Abern MR. Estrogens and prostate cancer. Prostate Cancer Prostatic Dis. 2019;22(2):185-94.

6. Culig Z, Santer FR. Androgen receptor signaling in prostate cancer. Cancer Metastasis Rev. 2014;33(2-3):413-27. 
7. Culig Z, Santer FR. Molecular aspects of androgenic signaling and possible targets for therapeutic intervention in prostate cancer. Steroids. 2013;78(9):851-9.

8. Aird J, Baird AM, Lim M, McDermott R, Finn SP, Gray SG. Carcinogenesis in prostate cancer: the role of long non-coding RNAs. Noncoding RNA Res. 2018;3(1):29-38.

9. Gamat M, McNeel DG. Androgen deprivation and immunotherapy for the treatment of prostate cancer. Endocr Relat Cancer. 2017;24(12):T297-310.

10. Bluemn EG, Coleman IM, Lucas JM, Coleman RT, Hernandez-Lopez S, Tharakan $\mathrm{R}$, et al. Androgen receptor pathway-independent prostate cancer is sustained through FGF signaling. Cancer Cell. 2017;32(4):474-89.

11. Grossman DC, Curry SJ, Owens DK, Bibbins-Domingo K, Caughey AB, Davidson KW, et al. Screening for prostate cancer: US preventive services task force recommendation statement. JAMA. 2018;319(18):1901-13.

12. Qaseem A, Barry MJ, Denberg TD, Owens DK, Shekelle P. Screening for prostate cancer: a guidance statement from the Clinical Guidelines Committee of the American College of Physicians. Ann Intern Med. 2013a;158(10):761-9.

13. Moyer VA. Screening for prostate cancer: US Preventive Services Task Force recommendation statement. Ann Intern Med. 2012;157(2):120-34.

14. Fenton JJ, Weyrich MS, Durbin S, Liu Y, Bang H, Melnikow J. Prostatespecific antigen-based screening for prostate cancer: evidence report and systematic review for the US preventive services task force. JAMA. 2018a;319(18):1914-31.

15. Qaseem A, Barry MJ, Denberg TD, Owens DK, Shekelle P. Screening for prostate cancer: a guidance statement from the Clinical Guidelines Committee of the American College of Physicians. Ann Intern Med. 2013b;158(10):761-9.

16. Bell N, Connor GS, Shane A, Joffres M, Singh H, Dickinson J, et al. Recommendations on screening for prostate cancer with the prostate-specific antigen test. CMAJ. 2014;186(16):1225-34.

17. Marcus PM, Kramer BS. Screening for Prostate Cancer with ProstateSpecific Antigen: What's the Evidence? Am Soc Clin Oncol Educ Book. 2012;2012:96-100.

18. Carter HB, Albertsen PC, Barry MJ, Etzioni R, Freedland SJ, Greene $\mathrm{KL}$, et al. Early detection of prostate cancer: AUA Guideline. J Urol. 2013;190(2):419-26.

19. Fenton JJ, Weyrich MS, Durbin S, Liu Y, Bang H, Melnikow J. Prostatespecific antigen-based screening for prostate cancer: evidence report and systematic review for the us preventive services task force. JAMA. 2018b;319(18):1914-31.

20. Djebali S, Davis CA, Merkel A, Dobin A, Lassmann T, Mortazavi A, et al. Landscape of transcription in human cells. Nature. 2012;489(7414):101-8.

21. Cui C, Zhai D, Cai L, Duan Q, Xie L, Yu J. Long Noncoding RNA HEIH promotes colorectal cancer tumorigenesis via counteracting miR939Mediated transcriptional repression of BCl-XL. Cancer Res Treat. 2018;50(3):992-1008.

22. Yuan JH, Yang F, Wang F, Ma JZ, Guo YJ, Tao QF, et al. A long noncoding RNA activated by TGF-beta promotes the invasion-metastasis cascade in hepatocellular carcinoma. Cancer Cell. 2014;25(5):666-81.

23. Liu C, Wu Y, Ma J. Interaction of non-coding RNAs and Hippo signaling: Implications for tumorigenesis. Cancer Lett. 2020;8:18.

24. Jarroux J, Morillon A, Pinskaya M. History, discovery, and classification of IncRNAs. Adv Exp Med Biol. 2017;1008:1-46.

25. Zhu J, Fu H, Wu Y, Zheng X. Function of IncRNAs and approaches to IncRNA-protein interactions. Sci China Life Sci. 2013;56(10):876-85.

26. Sahu D, Ho SY, Juan HF, Huang HC. High-risk, expression-based prognostic long noncoding RNA signature in neuroblastoma. J NCl Cancer Spectr. 2018;2(2):15.

27. Hao S, Yao L, Huang J, He H, Yang F, Di Y, et al. Genome-wide analysis identified a number of dysregulated long noncoding RNA (InCRNA) in human pancreatic ductal adenocarcinoma. Technol Cancer Res Treat. 2018;17:1876016077.

28. Jing H, Qu X, Liu L, Xia H. A Novel Long Noncoding RNA (IncRNA) LL22NC03-N64E91, promotes the proliferation of lung cancer cells and is a potential prognostic molecular biomarker for lung cancer. Med Sci Monit. 2018;24:4317-23.

29. Chan JJ, Tay Y. Noncoding RNA:RNA regulatory networks in cancer. Int J Mol Sci. 2018;19:5.

30. Shi T, Gao G, Cao Y. Long noncoding RNAs as novel biomarkers have a promising future in cancer diagnostics. Dis Markers. 2016;2016:9085195.
31. Brunner AL, Beck AH, Edris B, Sweeney RT, Zhu SX, Li R, et al. Transcriptional profiling of long non-coding RNAs and novel transcribed regions across a diverse panel of archived human cancers. Genome Biol. 2012;13(8):R75.

32. Yan $X$, Hu Z, Feng $Y$, Hu X, Yuan J, Zhao SD, et al. Comprehensive genomic characterization of long non-coding RNAs across human cancers. Cancer Cell. 2015;28(4):529-40.

33. Khandelwal A, Bacolla A, Vasquez KM, Jain A. Long non-coding RNA: a new paradigm for lung cancer. Mol Carcinog. 2015;54(11):1235-51.

34. Yuan Q, Chu H, Ge Y, Ma G, Du M, Wang M, et al. LncRNA PCAT1 and its genetic variant rs 1902432 are associated with prostate cancer risk. J Cancer. 2018;9(8):1414-20.

35. Ye Y, Li SL, Wang SY. Construction and analysis of mRNA, miRNA, IncRNA, and TF regulatory networks reveal the key genes associated with prostate cancer. PLoS ONE. 2018;13(8):e198055.

36. Mohler JL, Antonarakis ES, Armstrong AJ, D'Amico AV, Davis BJ, Dorff T, et al. Prostate Cancer, Version 2.019, NCCN clinical practice guidelines in oncology. J Natl Compr Canc Netw. 2019;17(5):479-505.

37. Kanehisa M, Furumichi M, Tanabe M, Sato Y, Morishima K. KEGG: new perspectives on genomes, pathways, diseases and drugs. Nucleic Acids Res. 2017:45(D1):D353-61.

38. Blake JACKDM. Gene ontology consortium: going forward. Nucleic Acids Res. 2015;43:D1049-56.

39. RNAcentral: a hub of information for non-coding RNA sequences. Nucleic Acids Res. 2019:47(1):D221-9.

40. Tang Z, Li C, Kang B, Gao G, Li C, Zhang Z. GEPIA: a web server for cancer and normal gene expression profiling and interactive analyses. Nucleic Acids Res. 2017;45(W1):W98-102.

41. Yang X, Du WW, Li H, Liu F, Khorshidi A, Rutnam ZJ, et al. Both mature miR17-5p and passenger strand miR-17-3p target TIMP3 and induce prostate tumor growth and invasion. Nucleic Acids Res. 2013:41(21):9688-704.

42. Gibb EA, Warren RL, Wilson GW, Brown SD, Robertson GA, Morin GB, et al. Activation of an endogenous retrovirus-associated long non-coding RNA in human adenocarcinoma. Genome Med. 2015;7(1):22.

43. Yang Z, Yu L, Wang Z. PCA3 and TMPRSS2-ERG gene fusions as diagnostic biomarkers for prostate cancer. Chin J Cancer Res. 2016;28(1):65-71.

44. Crawford ED, Rove KO, Trabulsi EJ, Qian J, Drewnowska KP, Kaminetsky JC, et al. Diagnostic performance of PCA3 to detect prostate cancer in men with increased prostate specific antigen: a prospective study of 1,962 cases. J Urol. 2012;188(5):1726-31.

45. Kretschmer A, Tilki D. Biomarkers in prostate cancer-current clinical utility and future perspectives. Crit Rev Oncol Hematol. 2017;120:180-93.

46. Fujita K, Nonomura N. Urinary biomarkers of prostate cancer. Int J Urol. 2018;25(9):770-9.

47. Wang $Y$, Hu Y, Wu G, Yang $Y$, Tang $Y$, Z Zhang $W$, et al. Long noncoding RNA PCAT-14 induces proliferation and invasion by hepatocellular carcinoma cells by inducing methylation of miR-372. Oncotarget. 2017;8(21):34429-41.

48. Shukla S, Zhang X, Niknafs YS, Xiao L, Mehra R, Cieslik M, et al. Identification and Validation of PCAT14 as Prognostic Biomarker in Prostate Cancer. Neoplasia. 2016;18(8):489-99.

49. White NM, Zhao SG, Zhang J, Rozycki EB, Dang HX, McFadden SD, et al. Multi-institutional Analysis Shows that Low PCAT-14 expression associates with poor outcomes in prostate cancer. Eur Urol. 2017;71 (2):257-66.

50. Lucas JM, Heinlein C, Kim T, Hernandez SA, Malik MS, True LD, et al. The androgen-regulated protease TMPRSS2 activates a proteolytic cascade involving components of the tumor microenvironment and promotes prostate cancer metastasis. Cancer Discov. 2014:4(11):1310-25.

51. Ko CJ, Huang CC, Lin HY, Juan CP, Lan SW, Shyu HY, et al. Androgeninduced TMPRSS2 activates matriptase and promotes extracellular matrix degradation, prostate cancer cell invasion, tumor growth, and metastasis. Cancer Res. 2015;75(14):2949-60.

52. Chen YW, Lee MS, Lucht A, Chou FP, Huang W, Havighurst TC, et al. TMPRSS2, a serine protease expressed in the prostate on the apical surface of luminal epithelial cells and released into semen in prostasomes, is misregulated in prostate cancer cells. Am J Pathol. 2010;176(6):2986-96.

53. Squire JM, Paul DM, Morris EP. Myosin and actin filaments in muscle: structures and interactions. Subcell Biochem. 2017:82:319-71.

54. Makowska KA, Hughes RE, White KJ, Wells CM, Peckham M. Specific myosins control actin organization, cell morphology, and migration in prostate cancer cells. Cell Rep. 2015;13(10):2118-25. 
55. Zhang HR, Lai SY, Huang LJ, Zhang ZF, Liu J, Zheng SR, et al. Myosin 1b promotes cell proliferation, migration, and invasion in cervical cancer. Gynecol Oncol. 2018;149(1):188-97.

56. Wang D, Zhu L, Liao M, Zeng T, Zhuo W, Yang S, et al. MYO6 knockdown inhibits the growth and induces the apoptosis of prostate cancer cells by decreasing the phosphorylation of ERK1/2 and PRAS40. Oncol Rep. 2016;36(3):1285-92.

57. Prevarskaya N, Skryma R, Shuba Y. Calcium in tumour metastasis: new roles for known actors. Nat Rev Cancer. 2011;11(8):609-18.

58. Prevarskaya N, Ouadid-Ahidouch H, Skryma R, Shuba Y. Remodelling of $\mathrm{Ca}^{2+}$ transport in cancer: how it contributes to cancer hallmarks? Philos Trans R Soc Lond B Biol Sci. 2014;369(1638):20130097.

59. Liu J, Han P, Li M, Yan W, Liu J, He J, et al. Histidine-rich calcium binding protein promotes growth of hepatocellular carcinoma in vitro and in vivo. Cancer Sci. 2015;106(10):1288-95.

60. Arvanitis DA, Vafiadaki E, Sanoudou D, Kranias EG. Histidine-rich calcium binding protein: the new regulator of sarcoplasmic reticulum calcium cycling. J Mol Cell Cardiol. 2011;50(1):43-9.
61. Haga RB, Ridley AJ. Rho GTPases: Regulation and roles in cancer cell biology. Small GTPases. 2016;7(4):207-21.

62. Song LJ, Liu Q, Meng XR, Li S, Wang LX, Fan QX, et al. DLC-1 is an independent prognostic marker and potential therapeutic target in hepatocellular cancer. Diagn Pathol. 2016:11:19.

63. Chen B, Xu M, Xu M. Upregulation of DLC-1 inhibits pancreatic cancer progression: Studies with clinical samples and a pancreatic cancer model. Oncol Lett. 2019;18(5):5600-6.

\section{Publisher's Note}

Springer Nature remains neutral with regard to jurisdictional claims in published maps and institutional affiliations.
Ready to submit your research? Choose BMC and benefit from:

- fast, convenient online submission

- thorough peer review by experienced researchers in your field

- rapid publication on acceptance

- support for research data, including large and complex data types

- gold Open Access which fosters wider collaboration and increased citations

- maximum visibility for your research: over $100 \mathrm{M}$ website views per year

At $\mathrm{BMC}$, research is always in progress.

Learn more biomedcentral.com/submissions 